\title{
The case for catchment areas for mental health services
}

\author{
Graham Thornicroft, Geraldine Strathdee and Sonia Johnson
}

\begin{abstract}
The establishment of mental health teams which take responslbility for small geographical catchment areas has been a fundamental element in the planning of community services in most Westem European countries over the last decade. This idea is challenged in the companion paper in this issue of Psychiatric Bulletin which refers to catchment areas as a "relic of the past". The case is put for cotchment areas in terms of their planning, sorvice dellvery and quality advantoges for the development of comprehensive inter-agency mental health services. In brief, it is argued that community mental health services are still in many areas pootty developed (Audit Commission, 1994; Faulkner of af, 1994), and that catchment areas are necessary but not suificient for their fuller reallsation.
\end{abstract}

\section{The development of catchment areas}

The early proponents of community care concentrated less on specifying the components of care than on developing the organisational framework within which such services could effectively be delivered. Phillipe Paumelle, working in Paris in the 1950s, formulated three essential principles: that services should provide for continuity, coordination and integration of care. To fulfil these requirements, he wrote that the planning and operation of services should take place at a defined local level. The concept of a 'sector' as the demonimator in local planning evolved and has subsequently gained wide support. Tansella (1991), in recognition of the vital role of such an infrastructure, reiterates that "what is important in community care is not only the number and characteristics of various services but the way in which they are arranged and integrated".

The first sectors emerged in France in the 1960s. In the USA the Community Mental Health Centres Act (1963) introduced the principle of a catchment area for each CMHC. In the 1970s sectors of varied sizes developed in Europe, from Germany with sectors of
250,000 to Sweden with 25-50,000. Italy most comprehensively adapted the concept by virtue of Law 178 which established sectors of 50-200,000 population.

Sectors are not only a concept of health services. In each local area in Britain, housing, social services and the police have geographically defined areas of responsibility. In planning services for the severely mentally ill it is necessary to ensure improved outcomes by implementing effective interventions in the following key areas: housing, welfare benefits, physical health, daily living skills, work and education. This can best be achieved by

Table 1. Planning advantages of catchment areas

Agreed inter-agency definition of the priority group High identification rates of the severely mentally III integrated care programme approach and care management

Clinical and social needs assessment

Development of a directory of local resources Appropriate senvices for local needs

Joint planning of hospltal and community beds

Inter-agency development of local day care

Development of work with local employers

Agreed protocols with local sector police

Potentlal for better knowledge of cost issues Greater budgetary clarity

Table 2. Service delivery advantages of catchment areas

Minimise patients lost to follow-up

Indlvidually tailored inter-agency patient reviews

Less use of crisis and in-patient facillities

Facilltates home treatment

Improved identity of staff with locallity

Clarity of functions of district teams

Improved inter-agency communication patterns

Improved knowledge and use of community resources Increased morale and support to all community

agencles

Allows comparative research and evaluation 
Table 3. Service quality advantages of catchment areas

Improved patient education and intervention

Less use of crisis and emergency senvices

Use of appropriate adult protocols

Greater support of relatives and carers

Defined responsibility for each patient

Improved communication for staff, patients and carers

Improved primary-secondary care communication

Table 4. Factors for consideration in defining catchment area boundaries

Socio-demographic composition of population

Social deprivation indices

Ethnic composition

Geographical characteristics

Age-sex structure

Social services boundaries and approved social worker structure

Health centre/group practice location

GP referral rates and patterns

Knowledge of psychiatric morbidity

Extent of sheltered housing

Number of old/new long-stay patients

Presence of a large institution

Local government planning regulations

Neighbourhood housing office and police sector boundaries

effective inter-agency working between primary and secondary health services, housing and social services.

A number of advantages have been claimed for sectorised services (Strathdee \& Thornicroft, 1992). The three primary arguments for catchment areas are that they fix responsibility for care with named staff, and that they encourage continuity of care and that they facilitate effective inter-agency working. Responsibility for each patient requiring a service is allocated to a specified team, which can make population and patient needs assessments, so minimising the number of patients lost to follow-up (Wing, 1992). In addition, the development of alternative types of sector team allows empirical investigation of their cost-effectiveness and acceptability. Where staff in the community agencies know each other and meet face to face, working to a common agenda services development is likely to proceed faster.

Where evaluations of sectorisation have been reported, the findings are favourable. In Nottingham, for example. Tyrer et al (1989) found reductions in the number of admissions
(5\%), duration of admissions (4\%), and use of in-patient beds $(38 \%)$. Similarly in Sweden, Hansson (1989) recorded falls in the number of admissions (20\%), beds days used (40\%), and compulsory admissions (25\%). The Mental Health Task Force London Study (Cochrane et al, 1994) highlighted the difficulties in planning community services where there were not co-terminous boundaries between the three key agencies (health, housing and social services).

Small geographical catchment areas are now the norm for adult mental health services in England and Wales. In a recent survey, 199 district health authorities were contacted. Most $(87 \%)$ responded and of these $81 \%$ $(n=140)$ reported that they had sectorised their mental health services (Johnson \& Thornicroft, 1993). Sectorisation had started in 1959 , with 1985 as the median year. In $63 \%$ $(n=86)$ of sectorised districts, a single team in each sector provides both continuing care and acute services, while in $10 \%(n=13)$ the sector has two teams for these separate functions. The median sector population was 60,000 , with a mean of 70,600 .

\section{Factors influencing catchment area boundaries}

The division of a district into smaller catchment areas is influenced by many considerations (Table 4). The most important issues are the rural or urban nature of the area, the presence of a river or other natural structure which impairs access; the need to achieve co-terminosity with either a social services boundary or general practice locations; and the division of the total district into areas which are manageable for the local mental health teams.

\section{The primary-secondary care interface}

The most serious arguments against rigid catchment areas arise where primary and secondary care boundaries are not coterminous. In this case there may be concern from family doctors, patients and their carers that a sectorised service may reduce their choice for a preferred local psychiatrist, and may promote generalist rather than specialist services. Primary care attachments of specialist staff can go some way towards addressing this dilemma by assessing all patients referred by practice staff, and only 
referring on to other catchment area teams those few patients who require ongoing specialist care. Indeed, a flexible application of catchment area boundaries is necessary for the system to work for the advantage of patients. In some cases the importance of an individual staff-patient relationship is such that it should override the strict application of what is an administrative convenience designed to improve the quality of service to most but not all patients.

In some rural areas and in smaller towns the ideal arrangement of co-terminous social services, and primary and secondary health services may occur. But in many metropolitan areas borough and primary care boundaries inter-weave. To rely on a primary care list alone for secondary care teams would potentially render some patients who are homeless, unregistered or who do not attend their GPs lost to contact, and this is more likely to occur for the more severely mentally ill (Harrison et al, 1994).

Current trends in British mental health services are clear: progressive reductions of long-term beds in hospital (Davidge et al 1993), policies which guide staff to target services on the most severely mentally ill (Department of Health, 1993), and continuing widespread concern about cases in which continuity between services and across time has been inadequate (North East Thames and South East Thames Regional Health Authorities, 1994). One fundamental building block of the NHS, which has allowed a public health perspective to guide health services, has been the catchment area. Without this, a mosaic of smaller service providers may together fail to provide any service to many patients, as the example of some parts of the USA shows. It is therefore reasonable, at this stage of the development of mental health services, to target as the first priority the most severely disabled patients by using mental health catchment area teams, and, as a second priority, to support, through GP practice attachments, primary care staff with the other $90 \%$ of mentally ill patients who are not referred on to specialist teams.

\section{References}

Audrt Commission (1994) Finding a Place. A Review of Mental Health Services for Adults. London: HMSO.

Cochrane, D. ConRoy, M. \& LewIS, R. (1994) A Profile of London's Mental Health Services: a report for the Mental Health Task Force London Project. London: Conrane Consulting.

DAvidge, M., EuAS, S., JAYEs, B. \& YATES, J. (1993) Survey of English Mental Illness Hospitals March 1993. InterAuthority Consultancy and Comparisons. University of Birmingham.

DEPARTMENT OF HEALTH (1993) The Health of the Nation. Key Area Handbook. Mental Illness. London: Department of Health.

FAulkner, A., Field, V. \& Munen, M. (1994) A Survey of Adult Mental Health Services. London: Sainsbury Centre for Mental Health.

HANSSON, L. (1989) Utilisation of psychiatric in-patient care. Acta Psychiatrica Scandinavica, 79, 571-578.

HARRISON, G., Mason, P., GlazebroOK. C., MEdLey, I. et al (1994) Residence of incident cohort of psychotic patients after 13 years of follow up. British Medical Journal, $\mathbf{3 0 8}$. 813-816.

JOHNSON, S. \& THORNICROFT, G. (1993) The sectorisation of psychiatric services in England and Wales. Social Psychiatry \& Psychiatric Epidemiology. 28, 45-47.

NORTH EAST THAMES AND SOUTH EAST THAMES REgIONAL HEALTH AUTHORTIES (1994) Report into the Inquiry into the Care and Treatment of Christopher Clunis. London: HMSO.

STRATHDEE, G. \& THORNICROFT, G. (1992) Community sectors of needs-led mental health services. In Measuring Mental Health Needs leds Thornicroft, G., Brewin. C. \& Wing. J.). London: Gaskell (Royal College of Psychiatrists).

TANSELlA, M. (1991) Community-based psychlatry: longterm pattern of care in South-Verona. Psychological Medicine, Supplement 19.

TYRER, P., TURNER, R. \& JOHNSON, A. (1989) Integrated hospital and community psychiatric services and use of inpatient beds. British Medical Journal, 299, 298-300.

WING. J. (1992) Epidemiologically Based Needs Assessment: mental illness. London: NHS Executive.

Graham Thornicroft, Director, Geraldine Strathdee, Consultant Community Psychiatrist. and Sonia Johnson. Project Co-ordinator for the Maudsley Continuing Care Study and Honorary Senior Registrar, PRiSM, Institute of Psychiatry. De Crespigny Park, London SE5 8AZ 